\title{
RACIONALIZAÇÃO DE FORMULÁRIOS
}

CLAUDE MACHLINE

"A técnica faz avanģar a civilização aumentando o número de operaçóes que o homem pode realizar automàticamente." - ALFRED NORTH WHITEHEAd

Na emprêsa moderna a maior parte das informações são adquiridas, transmitidas e preservadas por meio de formulários que permitem o preenchimento rápido e sistemático da comunicação e facilitam sua leitura e consulta. Em determinado momento da evolução de uma emprêsa um formulário específico pode estar fazendo falta. Em outros casos o impresso existente não sati, faz, quer por ser difícil de ser preenchido e inútil, que $r$ por estar confeccionado de maneira inadequada. A criação e a modificação de formulários constituem, pois, tarefas para as quais o administrador precisa estar preparado.

Um formulário deve satisfazer numerosas exigências em relação às características físicas do papel, ao texto e à disposição dos dados. Neste artigo enunciam-se, ilustrados por numerosos exemplos, três princípios de confecção e racionalização de formulários .

\section{CLASSIFICAÇÃO DOS FORMULÁRIOS}

Formulário é o documento padronizado que se destina a receber, transmitir e preservar informes. Compreende uma parte impressa fixa e espaços em brarco para preen- 
chimento. Funciona como filtro selecionador de dados relevantes, como fórmula para mecanizar o seu lançamento e como repositório para a sua guarda.

Manuais de operações, relatórios, cartas e instruções de serviço não são formulários, nem tampouco prospetos, listas de preços e circulares. Não obstante, muitos princípios de racionalização de formulários são válidos para êsses documentos também.

Os formulários podem ser classificados de muitas maneiras. Apresentamos, a seguir, algumas delas:

- Conforme o destino - (a) internos e (b) externos.

- Conforme o número de vias - (a) simples e (b) com cópias.

- Conforme o método de impressão - (a) por máquinas de escritório (copiadoras, mimeógrafos, multiplicadoras Multilith etc.) e (b) por máquinas industriais (de impressão litográfica offset, de rotogravura etc.) .

- Conforme a maneira de preenchimento - (a) manuscritos (a lápis ou a tinta); (b) a máquina de escrever; (c) a máquina contábil simples; (d) por aparelhos (mecânicos ou eletrônicos) de processamento de dados; e (e) pressão tipográfica, litográfica, offset, de rotogravura, de formulário contínuo etc.) .

- Conforme o setor emitente - (a) de compras (tais como ordens de compra, documentos para importação, documentos para concorrências); (b) de contabilidade (fôlhas de pagamento, comprovantes, declarações de impostos, faturas, livros contábeis e fiscais, notas fiscais, recibos); (c) de finanças (cheques, demonstrações da situação da emprêsa nos bancos); (d) de pessoal (cartões de ponto, solicitações de emprêgo, relações-de-dois-terços, relações de menores); (e) de produção (fichas de estoque, listas de componentes, ordens de produção); $(f)$ de verdas (fichas de cadastro, pedidos); e (g) gerais (papéis de correspondência, de expediente etc.) .

- Conforme a operação realizada - destinados a: (a) acusar recebimentos; (b) analisar; (c) autorizar; (d) 
cancelar; (e) candidatar-se; (f) certificar; (g) concordar; (h) controlar; ( $i)$ devolver; $(j)$ encaminhar; $(k)$ encomendar; (l) avaliar; $(m)$ identificar; $(n)$ inspecionar; $(o)$ instruir; $(p)$ notificar; $(q)$ programar; $(r)$ reclamar; $(s)$ registrar; $(t)$ relatar; $(u)$ requisitar; e $(v)$ tabular.

\section{PRIMEIRO PRINCÍPIO}

São três os princípios de racionalização de formulários . O primeiro enuncia-se assim: a responsabilidade pelo contrôle dos formulários deve ser centralizada. Nas emprêsas pequenas e médias uma pessoa, trabalhando em tempo parcial, poderá desempenhar essa função. Será, em geral, o chefe do escritório ou o gerente administrativo. Nas emprêsas de grande porte existe muito maior número de formulários; seu volume tende a crescer com o número de funcionários e a dispersão geográfica da organização. Será conveniente nesse caso que haja uma pessoa trabalhando em tempo integral para desircumbir-se dessa tarefa, de preferência um engenheiro ou um administrador profissional, prático em análise de métodos e sistemas.

O contrôle centralizado evitará os seguintes inconvenientes:

1) Proliferação de formulários — às vêzes quase idênticos - em diversas seções ou filiais da emprêsa. A criação de novos formulários resulta, não raro, da ignorância da existência de formulário idêntico em outra seção.

2) Criação de formulários que, por não seguirem as regras de racionalização compreendidas no terceiro principio, que adiante examinaremos, são ineficientes. Logo que um departamerto auxiliar - como o de planejamento $\epsilon$ contrôle da produção, ou o de contrôle-de-qualidade ou ainda, o de auditoria - é criado numa emprêsa, os seus responsáveis tendem a elaborar formulários próprios ("que já deram certo em outras emprêsas”), sem antes indager da possibilidade de os formulários já existentes serem adaptados às necessidades dos departamentos recém-criados. Exemplo frisante é o que ocorre com alguns documentos de contrôle da produção, os quais, mediante li- 
geiras modificações, podem muitas vêzes ser adaptados às necessidades do contrôle-de-qualidade, evitando-se, assim, a criação de formulários especializados.

As principais funções do contrôle centralizado de formulários são as seguintes:

- Análise dos formulários existentes e análise da necessidade de se criarem novos formulários. Criação e melhoria de formulários. Uma das primeiras tarefas do encarregado do contrôle central de formulários é a de colecionar, em pastas, modelos de todos os formulários existentes. Ao solicitar a entrega de amostras de formulários interdepartamentais, é bom lembrar que êstes são, na maioria das vêzes, mimeografados, e que os chefes de seção não gostam, em geral, de entregá-los a intrusos. Convém pedir a entrega de, pelo menos, três exemplares de cada formulário, a fim de classificá-los:

a) em seqüência numérica contínua (de 001 em diante);

b) por seções de origem (contabilidade, finanças, produção etc.);

c) por sistema de impressão (impressos, mimeografados, etiquêtas etc.).

- Contrôle centralizado do estoque de formulários. Fìsicamente, êsse estoque pode ser atribuído ao almoxarifado para evitar a criação de mais um cargo .

- Contatos com os impressores (externos e/ou internos) para encomenda e feitura dos formulários. Regra con veniente a tôda a emprêsa é que as encomendas de for mulários aos impressores (externos ou internos) sejam feitas por um único responsável.

SEGUNDO PRINCÍPIO

O segundo princípio de racionalização dos formulário enuncia-se da seguinte maneira: um formulário sòment deverá ser criado se tiver finalidade específica, e sòment deverá ser mantido depois de as tentativas de supressã simples ou de fusão com outro formulário não se teren mostrado praticáveis. 
A criação de um formulário justifica-se nas condições seguintes:

A) Quando se deseja fixar a responsabilidade de alguém por uma tarefa. Assim, era hábito dos funcionários de certa emprêsa levar para casa, informalmente emprestados, certos aparelhos, como máquinas fotográficas e gravadores de fita. Não havia anotações dos empréstimos, o que causava delongas nas devoluções, esquecimentos e extravios. A criação de um documento para registro dos empréstimos veio sanar a falha.

B) Quando é necessário registrar o estado de uma operação em determinado ponto. Uma ficha para inspeção de peças no final de uma linha de montagem constitui exemplo de impresso criado com essa finalidade.

C) Quando se quer transmitir dados precisos de um ponto para outro. Um relatório de análise química tem essa função.

D) Quando dados importantes têm de ser registrados. Uma ficha de pedido de emprêgo tem principalmente êsse objetivo.

Em todos êsses casos é necessário que a ocorrência seja repetitiva, de maneira que o uso do formulário venha reduzir o tempo requerido para escrever a informação sem que a busca do formulário aumente o tempo de preparação da tarefa .

Nenhuma das circunstâncias seguintes justifica a criação de um formulário:

A) Informes idênticos provirem de outra seção com a qual as relações não sejam boas.

B) Os informes chegarem com atraso por terem de atravessar, necessàriamente, muitas seções. Há quem procure, então, - errôneamente - ir diretamente à fonte de informação para lá coligir os dados e depois registrá-los em formulário "particular".

C) Não serem os informes fornecidos na disposição exata que o chefe da seção deseje. Êle cria, então, nôvo formu- 
lário "particular" para satisfazer seu sentido estético, sem que se elimine o formulário paralelo - um êrro.

D) O simples desejo de evidenciar a atividade de um departamento ou de um cargo recém-criado, dando a entender, por outro lado, que os antecessores não tenham administrado de maneira competente.

A existência de um contrôle central de formulários permite, em parte, eliminar essas ocorrências.

Muitas deficiências administrativas podem ser sanadas. pela criação de um formulário, pois os encarregados de setor não são infalíveis e estão sujeitos a esquecimentos, caprichos e preconceitos. O formulário existe para auxiliar a memória e definir as tarefas de maneira inequívoca.

Em certa organização não havia formulário de requisição para pedidos de compra, isto é, um documento por meio do qual os chefes de seção pudessem solicitar ao departamento de compras o atendimento de suas necessidades de material; eram obrigados, por isso, a fazer verbalmente essas requisições: Em conseqüência, havia demora sistemática nas compras, bem como esquecimentos por parte do comprador, sendo o interessado, às vêzes, forçado a repetir sua encomenda ao comprador. Ademais, produziam-se erros quanto às especificações, às quantidades necessárias e ao prazo de entrega desejado. A criação de um formulário veio sanar essa deficiência.

Não é o caso de discutir aqui as vantagens e desvantagens da comunicação escrita em relação à verbal, ponto, aliás, crucial em tôda a emprêsa. A comunicação ideal, que é a verbal seguida de confirmação escrita, combina as vantagens de ambas: ao calor humano e à rápidez do contato direto alia o registro da informação e e fixação da responsabilidade.

Formulários destinados a controlar o uso de ferramentas numa oficina contribuirão para evitar o seu desaparecimento. Ordens de serviço numa garagem evitarão erros e esquecimentos nos consertos dos carros. Ordens de manutenção, fichas de lubrificação, registros de reclamação, fichas destinadas a registrar as causas de interrupção no 
funcionamento das máquinas são exemplos de documentos muito necessários, cuja criação não constitui mero capricho burocrático.

Na medida em que, em determinada situação, a experiência passada tiver provado que erros e omissões graves foram cometidos, justifica-se a tentativa de usar um formulário para desenvolver o sentimento de responsabilidade e sanar as falhas.

Os mais frisantes resultados na racionalização de papéis obtêm-se pela eliminação de formulários duplicados ou por sua integração em formulários já existentes. Nesse sentido a simplificação do sistema de escritório funciona como a simplificação de métodos na fábrica, onde se visa, antes de mais nada, a eliminar os movimentos e trabalhos supérfluos.

Vejamos dois exemplos de supressão de documentos inúteis, por fusão entre si ou com outros formulários .

1) A administração de uma escola afixava, mensalmente, no quadro de avisos de cada uma das quatro séries do curso superior a relação de faltas dos alunos, sob forma de lista que a secretária datilografava cada vez, conforme o modêlo mostrado na Figura 1 .

Além do mais, de cada sabatina, prova ou trabalho prático, a secretária datilografava os resultados, cada vez, de maneira idêntica. $O$ mesmo trabalho era feito para a relação final de faltas e das médias finais de cada aluno.

Criou-se um formulário, representado na Figura 2, com tantas colunas quantas eram necessárias para :epresentar as faltas e as notas correspondentes a todo o ano c scolar. O formulário era retirado mensalmente do quadro de avisos, atualizado com lançamentos na coluna correspondente ao mês, e novamente afixado. Ademais, como a relação de alunos era idêntica em todos os cursos de cada série, a secretária datilografava várias vias das listas de nomes, utilizando papel carbono. A redução do trabalho de datilografia foi da ordem de $98 \%$ e a economia de paf 1 chegou a cêrca de $87 \%$. 
Figura 1: Relação de Faltas (modêlo antigo)

ESCOLA SUPERIOR DE QUIMICA

ANO 3. CURSO: ENGENHARIA INDUSTRIAL RELAÇÃO DAS FALTAS OCORRIDAS DURANTE

O MES DE NOVEMBRO DE 1963

ABELARDO GOMES

ALOÍSIO DA SILVA

BENJAMIN MAYER

BERNARDO MOTTA

2) Certa emprêsa do ramo de produtos eletrodomésticos dividia o território nacional, para efeito de vendas, em seis setores (Norte, Centro, Rio, São Paulo, Oeste e Sul), por sua vez subdivididos em filiais correspondentes aos Estados mais importantes. O departamento de vendas publicava um relatório mensal composto de seis páginas, mostrando, respectivamente:

a) a colocação das filiais por cobertura das cotas ( $F$ igura 3 );

b) a colocação das filiais por índice de aumento de vendas (Figura 4);

c) a colocação das filiais por montante de vendas ( $F$ igura 5);

d) a colocação dos setores por cobertura das cotas;

e) a colocação dos setores por índice de aumento de vendas;

f) a colocaçăo dos setores por montante de vendas. 
Cada período de análise compreendia a soma dos meses acumulados desde novembro (início do exercício) até o mês em foco. Em cada página dêsse relatório apareciam os nomes de tôdas as filiais ou de todos os setores e, pelo menos duas vêzes, as vendas realizadas no ano, as do ano anterior e as cotas. Para saber como uma filial se comportava em relação à cobertura de sua cota, ao seu índice de aumento de vendas e ao seu montante de vendas, era necessário folhear sucessivamente três páginas.

Dispuseram-se as seis colocações numa fôlha única ( $F$ igura 6), o que reduziu consideràvelmente o trabalho de datilografia e análise. Além do mais, outros dados úteis (médias mensais e previsão acumulada) que apareciam em outros relatórios que puderam ser suprimidos, foram colocados nesse relatório único. Maior espaço colunar foi obtido arredondando-se os dados para frações decimais de milhões de cruzeiros.

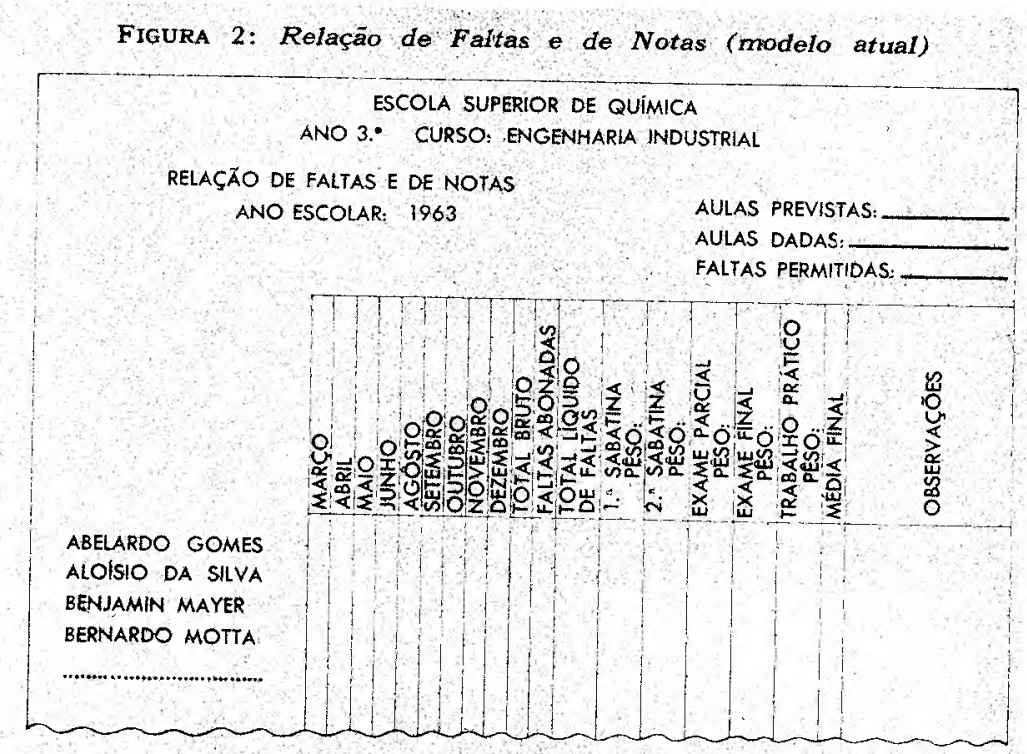

Simplificação semelhante foi introduzida no relatório de colocação mensal dos viajantes, reduzindo-se quinze páginas a cinco. 
FIGURA 3: Fragmento de uma Comparação de Vendas de Filiais por Cobertura de Cotas (modêlo antigo)

\begin{tabular}{|c|c|c|c|c|c|}
\hline \multicolumn{6}{|c|}{$\begin{array}{l}\text { DIRETORIA DE MERCADO } \\
\text { COMPARAÇÃO DE VENDAS }\end{array}$} \\
\hline \multicolumn{6}{|c|}{ COLOCAÇAOO DAS FIIIAIS POR COBERTURA DE COTAS NAS VENDAS ACUMULADAS } \\
\hline $\begin{array}{l}\text { CLASSI } \\
\text { FICAÇÃO }\end{array}$ & FILIAIS & $===$ & COTAS & DIFERENCCAS & $\begin{array}{l}\% \overline{D E} \\
\text { COBERTURA }\end{array}$ \\
\hline 1.8 & RIBEIRÃO PRETO & 32.923 & 23.489 & 9.434 & 140,1 \\
\hline $2 .{ }^{\mathrm{x}}$ & PÓRTO ALEGRE & 113.293 & 92.888 & 20.405 & 122,0 \\
\hline $3 . n$ & RECIFE & 90.964 & 75.478 & 15.486 & 120,5 \\
\hline $14 *^{*}$ & UBERLÂNDIA & 65.273 & 67.876 & 2.603 & 96,2 \\
\hline $15 .^{n}$ & MANÁUS & 3.963 & 5.747 & & \\
\hline & BRASHL & 1.325 .864 & 1.283 .887 & 41.977 & 103,3 \\
\hline MÉD & IAS MENSSAIS & 220.977 & 213.981 & 6.996 & \\
\hline
\end{tabular}

Figura 4: Fragmento de uma Comparação de Vendas de Filiais por Indice de Aumento de Vendas (modêlo antigo)

\begin{tabular}{|c|c|c|c|c|c|}
\hline \multicolumn{6}{|c|}{$\begin{array}{c}\text { DIRETORIA DE MERCADO } \\
\text { COMPARACÃO DE VENDAS } \\
\text { PERIODO: DE NOVEMBRO A ABRIL }\end{array}$} \\
\hline \multicolumn{6}{|c|}{ COLOCAÇÃO DAS FILIAIS POR INDICE DE AUMENTO NAS VENDAS ACUMULADAS } \\
\hline $\begin{array}{l}\text { CLASS! } \\
\text { FICAÇAOO }\end{array}$ & FILIAIS & 1961 & 1962 & DIFERENÇAS & $\begin{array}{c}\% \text { DE } \\
\text { AUMENTO }\end{array}$ \\
\hline $1 .{ }^{*}$ & RECIFE & 48.914 & 90.964 & 42.050 & 86,0 \\
\hline $2 .{ }^{\mathrm{a}}$ & RIBEIRÃO PRÊTO & 18.028 & 32.923 & 14.895 & 82,6 \\
\hline $3 . \mathrm{a}$ & PORTO ALEGRE & 62.913 & 113.293 & 50.380 & 80,1 \\
\hline
\end{tabular}


Figura 5: Fragmento de uma Comparação de Vendas de Filiais por Montante de Vendas (modêlo antigo)

\begin{tabular}{|c|c|c|c|c|c|}
\hline \multicolumn{6}{|c|}{$\begin{array}{l}\text { DIRETORIA DE MERCADO } \\
\text { COMPARAÇÃO DE VENDAS }\end{array}$} \\
\hline PERIODO: & DE NOYEMBRO & A ABRIL & & & , \\
\hline \multicolumn{6}{|c|}{ COLOCAÇĀO DAS FILIAIS } \\
\hline $\begin{array}{l}\text { CLASSI } \\
\text { FICAÇÃO }\end{array}$ & FiLIAIS & 1967 & 1962 & DIFERENÇAS & $\begin{array}{l}==\overline{\overline{\%}}== \\
\text { DE AUMENTO }\end{array}$ \\
\hline $1.3^{3}$ & RIO DE JANEIRO & 178.003 & 296.528 & 118.525 & 66,6 \\
\hline 2." & $\begin{array}{l}\text { SÃO PAULO } \\
\text { (CAPITAL) }\end{array}$ & 162.964 & 269.156 & 106.192 & 65,2 \\
\hline 3." & $\begin{array}{l}\text { SÃO PAULO } \\
\text { (INTERIOR) }\end{array}$ & 97.340 & 146.578 & 49.238 & 50,6 \\
\hline
\end{tabular}

Figura 6: Análise de Vendas (modêlo nôvo)

\begin{tabular}{|c|c|c|c|c|c|c|c|c|c|c|c|}
\hline \multicolumn{3}{|c|}{$\frac{\text { DIRETORIA DE MERCADO }}{\text { Divisbo do Estalistica }}$} & \multicolumn{8}{|c|}{$\frac{\text { ANÁLISE DAS VENDAS NAS FILIAIS E NOS SETORES }}{\text { Perído: DE NOVEMBRO A JULHO }(9 \text { meses }}$} & \\
\hline \multirow[t]{3}{*}{ Distribuiçäo } & \multirow{3}{*}{\multicolumn{2}{|c|}{$\begin{array}{l}\text { Médias mensais } \\
\text { do ano } \\
\text { (12 meses) } \\
\text { (Crs mithros) }\end{array}$}} & \multirow{2}{*}{\multicolumn{2}{|c|}{$\begin{array}{l}\text { Vendas acumis- } \\
\text { ladas até a } \\
\text { mês de fulho }\end{array}$}} & \multirow{4}{*}{$\begin{array}{c}\text { Previ- } \\
\text { säo p } \\
62 \text { acu- } \\
\text { mulado } \\
\text { ałé a } \\
\text { mês } \\
\text { (Cr\$ mi- } \\
\text { (thós) }\end{array}$} & \multirow{4}{*}{$\begin{array}{c}\% \text { de } \\
\text { cumen- } \\
10 \\
\frac{62}{6 !}\end{array}$} & \multirow{4}{*}{$\begin{array}{l}\text { \% de } \\
\text { cober- } \\
\text { tura } \\
\text { dos } \\
\text { previ- } \\
\text { söes }\end{array}$} & \multicolumn{3}{|c|}{ Classifficą̧ão } & \multirow{4}{*}{ 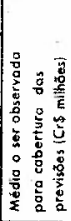 } \\
\hline & & & & & & & & \multirow{3}{*}{ 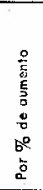 } & \multirow{3}{*}{ 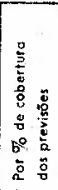 } & \multirow{3}{*}{ 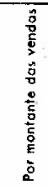 } & \\
\hline & & & \multicolumn{2}{|c|}{ (Cr\$ mithöes\}) } & & & & & & & \\
\hline TOTAIS & 1960 & 1961 & 1961 & 1962 & & & & & & & \\
\hline \multicolumn{12}{|c|}{ FILIAIS } \\
\hline $\begin{array}{l}\text { SÄO PAULO (Copital) } \\
\text { SÄO PAULO (lnterior) } \\
\text { RIO DE JANEIRO } \\
\text { BELO HORIZONTE } \\
\text { UBERLANDIA } \\
\text { BAURU } \\
\text { RIBEIRÄO PRÉTO } \\
\text { PORTO ALEGRE } \\
\text { LONDRINA } \\
\text { CURITBA } \\
\text { RECIFE } \\
\text { SALVADOR } \\
\text { FORTALEZA } \\
\text { BELEM } \\
\text { MANAUS }\end{array}$ & $\begin{array}{r}23,4 \\
11,2 \\
23,7 \\
6,4 \\
5,1 \\
3,8 \\
1,0 \\
8,3 \\
4,0 \\
2,4 \\
7,3 \\
4,2 \\
2,4 \\
2,1 \\
0,7\end{array}$ & $\begin{array}{r}30,1 \\
16,1 \\
32,8 \\
9,3 \\
6,7 \\
5,6 \\
3,2 \\
10,5 \\
4,8 \\
3,6 \\
8,1 \\
5,5 \\
4,0 \\
2,9 \\
0,9\end{array}$ & $\begin{array}{r}269,5 \\
144,2 \\
290,2 \\
80,8 \\
61,3 \\
48,0 \\
28,4 \\
95,5 \\
44,6 \\
32,5 \\
74,6 \\
50,0 \\
3.5,1 \\
25,8 \\
7,1\end{array}$ & $\begin{array}{r}406,4 \\
214,4 \\
433,3 \\
132,6 \\
93,5 \\
67,0 \\
47,3 \\
158,1 \\
64,9 \\
54,4 \\
113,1 \\
77,0 \\
53,6 \\
36,5 \\
8,3\end{array}$ & $\begin{array}{r}397,9 \\
208,4 \\
461,2 \\
126,1 \\
101,8 \\
72,0 \\
33,2 \\
139,4 \\
64,1 \\
49,2 \\
113,2 \\
72,6 \\
48,6 \\
36,0 \\
-\end{array}$ & $\begin{array}{l}50,8 \\
48,7 \\
49,3 \\
53,0 \\
52,5 \\
39,6 \\
66,5 \\
65,5 \\
45,5 \\
67,4 \\
51,6 \\
54,9 \\
52,7 \\
41,5 \\
18,9\end{array}$ & $\begin{array}{r}102,1 \\
102,9 \\
93,9 \\
98,0 \\
91,8 \\
93,0 \\
134,5 \\
113,5 \\
101,2 \\
110,6 \\
99,9 \\
106,0 \\
110,3 \\
101,4 \\
-\end{array}$ & 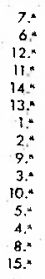 & 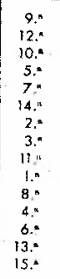 & 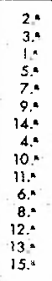 & $\begin{array}{r}44,2 \\
23,2 \\
60,6 \\
14,8 \\
14,0 \\
9,7 \\
3,9 \\
15,5 \\
7,1 \\
5,5 \\
12,6 \\
8,1 \\
5,4 \\
4,0 \\
\end{array}$ \\
\hline \multicolumn{12}{|c|}{ SETORES } \\
\hline $\begin{array}{l}\text { SÄO PAULO (Capital) } \\
\text { SÃO PAULO (mierier) } \\
\text { CENTRO } \\
\text { OESTE } \\
\text { SUI } \\
\text { NORTE } \\
\end{array}$ & $\begin{array}{l}23,4 \\
11,2 \\
23,7 \\
17,2 \\
14,7 \\
16,7 \\
\end{array}$ & $\begin{array}{l}30,1 \\
16,1 \\
32,8 \\
24,8 \\
18,9 \\
2 \mathrm{I}, 4 \\
\end{array}$ & $\begin{array}{l}269,5 \\
144,2 \\
290,2 \\
218,5 \\
172,6 \\
192,6 \\
\end{array}$ & $\begin{array}{l}406,4 \\
214,4 \\
433,3 \\
331,4 \\
277,4 \\
288,5 \\
\end{array}$ & $\begin{array}{l}397,9 \\
208,4 \\
461,2 \\
335,1 \\
252,6 \\
270,4 \\
\end{array}$ & $\begin{array}{l}50,8 \\
48,7 \\
49,3 \\
51,7 \\
60,7 \\
49,8 \\
\end{array}$ & $\begin{array}{r}102,1 \\
102,9 \\
93,9 \\
98,9 \\
109.8 \\
100,7 \\
\end{array}$ & $\begin{array}{l}3 . \\
6: \\
5: \\
2: \\
1 .: \\
4:\end{array}$ & $\begin{array}{l}3: \\
60 \\
5: \\
2: \\
1 .\end{array}$ & $\begin{array}{l}2: \\
6: \\
1: \\
5: \\
4:\end{array}$ & $\begin{array}{l}44,2 \\
23,2 \\
60,6 \\
38,4 \\
28,1 \\
30,0 \\
\end{array}$ \\
\hline BRAS II & 106,9 & 144,1 & $1,287,6$ & $1.951,4$ & $1.925,6$ & 51,5 & 101,3 & & $-x-$ & $\therefore$ & 214,0 \\
\hline
\end{tabular}


O terceiro princípio de racionalização de formulários refere-se à sua feitura. Enuncia-se assim: deve-se procurar melhorar todos as formulários sob os aspectos das características físicas, do texto e da disposição gráfica. Assemelha-se ao principio de racionalização do trabalho, que afirma: há ưa maneira melhor de realizar qualquer tarefa, que deve ser obtida pela análise pormenorizada dos métodos.

Existem regras definidas, expostas adiante, para a racionalização dos formulários, que dizem respeito aos pontos: seguintes: (a) características físicas do papel (formato, gramatura, tipo e côr); (b) texto; e (c) disposição gráfica.

FORMATO DO PAPEL

O espaço que os dizeres a serem registrados no formulário vão ocupar condiciona, em suas grandes linhas, o formato dêste. Para determinar as dimensões precisas do formulário o administrador deve adotar as dimensões padronizadas que mais se aproximem das dimensões necessárias .

Três séries de dimensões padronizadas estão em uso entre nós:

1. a A série ofício. E constituída de dois tamanhos: (a) o tamanho "ofício", de dimensões $220 \times 330 \mathrm{~mm}$; e (b) o tamanho "ofício-duplo" ou "almaço", que mede $440 \mathrm{x}$ $330 \mathrm{~mm}$. Esta série é utilizada principalmente na mimeografia de impressos, na confecção de apostilas e na correspondência oficial.

2. a) A série polegada. Nos países anglo-saxônicos são usados pelo menos vinte formatos desta série. No Brasil as dimensões originais foram alteradas, e as usadas são as seguintes: 
Medidas em polegadas
$3 \times 5$
$4 \times 6$
$5 \times 8$
$6 \times 9$
$6 \times 11$
$7 \times 10$
$8 \times 11$

Medidas equivalentes em mm

$$
\begin{array}{r}
76 \times 127 \\
102 \times 152 \\
127 \times 203 \\
152 \times 228 \\
152 \times 280 \\
177 \times 254 \\
204 \times 279
\end{array}
$$

Os fabricantes de arquivos de aço especificam em polegadas as dimensões de suas gavetas, pastas e fichas.

3. a) A série métrica. Os formatos desta série baseiam-se no sistema métrico. É a série recomendada pelas normas internacionais de padronização e pela Associação Brasileira de Normas Técnicas. Aplicam-se a desenhos técnicos, impressos, edições de livros, revistas e jornais, conforme mostra o Quadro 1.

Na primeira e na segunda coluna do Quadro 1 encontram-se a denominação e as dimensões do formato. O formato "A-O", que é o formato-base da série, corresponde à área de um metro quadrado $\left(841 \times 1189 \mathrm{~mm}=1 \mathrm{~m}^{2}\right)$. As dimensões dos formatos sucessivos mantêm entre si a relação de 1 para $\sqrt{2}$. Por exemplo, $1189: 841=1,4137$ $=\sqrt{2}$. Cada formato é a metade do anterior e o dóbro do seguinte, conforme se nota na Coluna 2 do Quadro 1 e na Figura 7.

Além dos formatos "principais" ou formatos "A", que constam do Quadro 1, as normas brasileiras recomendam outros, especiais, para a fabricação de objetos estreitos envelopes, por exemplo. São derivados dos formatos " $A$ " divididos, longitudinalmente, em 2, 4 e 8 partes.

As medidas externas estão indicadas na Coluna 2 do Quadro 1. Devido à existência de margens nos quatro lados da página, o texto impresso ocupa espaço menor, deno- 
minado "caixa" ou "espelho". Adotam-se, em geral, as margens indicadas na Coluna 3 . As dimensões do espetho são indicadas na Coluna 4 . Na Coluna 5 são mencionados os usos mais comuns dos diversos formatos. O padrão "A-4", de medidas $210 \times 297 \mathrm{~mm}$, denominado "formato-carta", tem extenso emprêgo no corte de papel para correspondência, notas fiscais e inúmeros outros documentos.

A padronização dos formatos visa a dois objetivos:

- Economia de papel - os formulários são recortados de "resmas", de dimensões bem estabelecidas, fornecidas às gráficas pelos fabricantes de papel. Portanto, se o formato escolhido fôr uma divisão exata da resma, evitam-se aparas (ou "refilos"), economizando-se, pois, papel.

- Facilidade de arquivamento - os arquivos de metal, as pastas e os porta-fichas são fabricados em dimensões padronizadas e os impressos deverão adaptar-se a essas dimensões para poderem ser arquivados com comodidade e sem perda de espaço.

Por via de regra, as fábricas de papel fornecem às gráficas as resmas de $\mathbf{5 0 0}$ fôlhas em dois formatos:

a) formato "alemão", "germano" ou "AA" (mede $760 \mathrm{x}$ $1120 \mathrm{~mm}$ ); e

b) formato "normal" ou "BB" (mede $660 \times 960 \mathrm{~mm}$ ).

A cartolina para fichas é fabricada nas dimensões seguintes:

a) formato "São Paulo" - $500 \times 660 \mathrm{~mm}$; e

b) formato "Rio" - $550 \times 730 \mathrm{~mm}$.

$80 \%$ dos impressos são feitos em papel; apenas $20 \%$ em cartolina. Além dos formatos "AA" e "BB", surgiram ùltimamente novos formatos de fôlhas de resma. Os mais freqüentes são os seguintes: $840 \times 1120,860 \times 1140$ e 880 x $1160 \mathrm{~mm}$. Observe-se que essas fôlhas de resma, de maiores dimensões que as dos tipos "AA" e "BB", corres- 


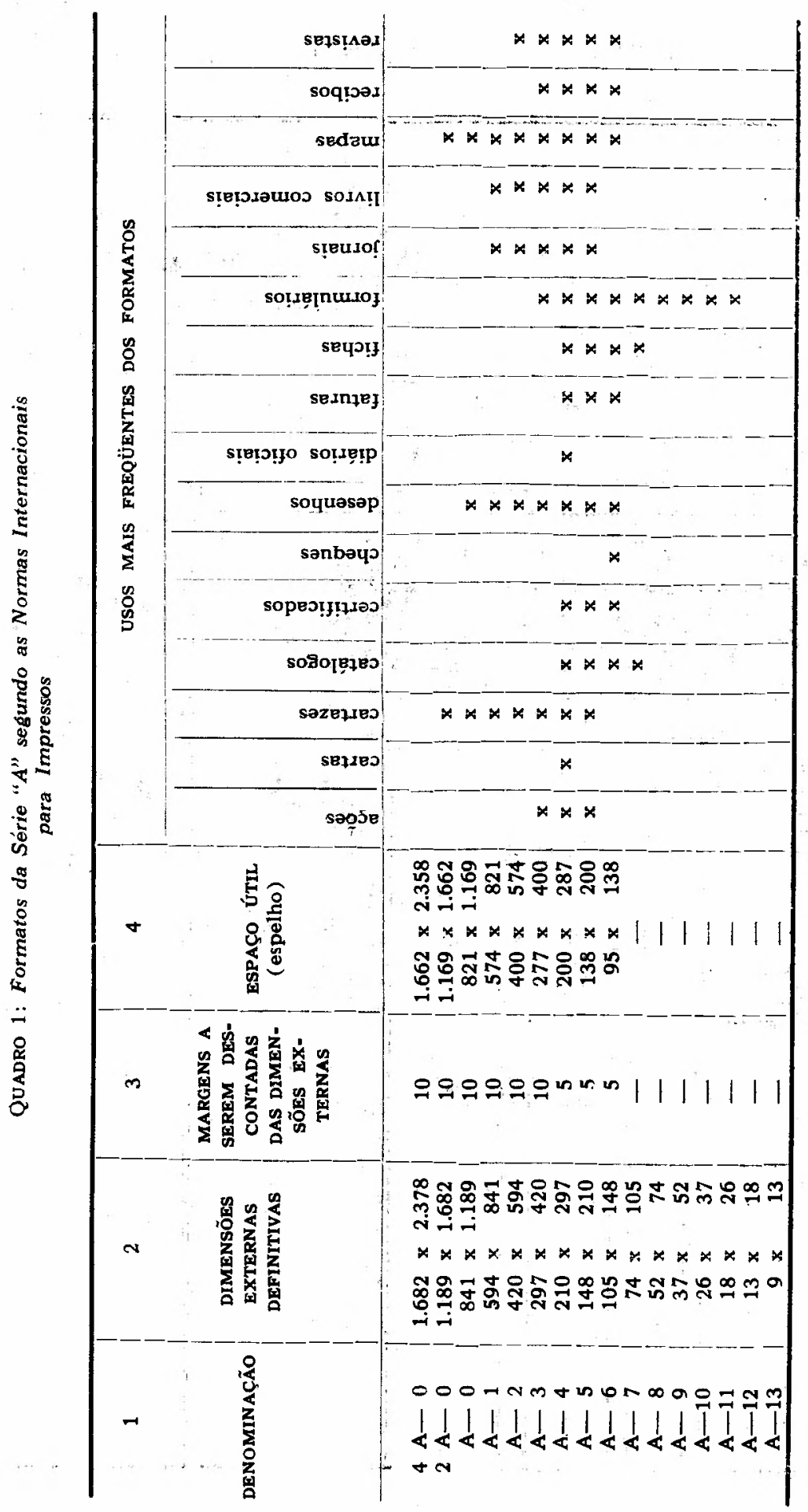


Figura 7: Formatos-Padróes dos Papéis Comerciais

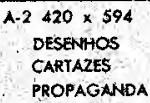

DEMENSOES EM MULMETROS

A-3 $297 \times 420$
OESENHOS
PAPEIS COMERCLALS
PORMULARIOS DE FABRICACAAO
CARTAZES
PROPAGANDA
REVISTAS

C.4 $229 \times 324$

A-4 $210 \times 297$

DESENHOS

FOLHA DE NORMAS

CARTA

LISIA DE PREÇOS

PAPÉS COMERCIAS

REVISTAS

AUTOS

ACHAS

Formulartos

C. $5162 \times 229$ ENVELOPES

A.5 $148 \times 210$

PAPEIS COMERCIAIS

MEMORANDO

FICHAS

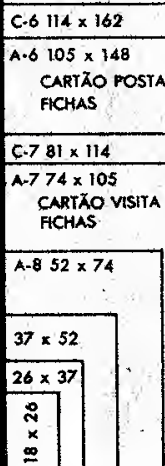


pondem a máquinas modernas, de maiores dimensões, que têm maior rendimento nas montagens. O formato " $B B$ " é o mais usado. Estima-se que $60 \%$ da produção de resmas de papel sejam do tipo "BB".

Ao cortar a fôlha de resma para obtenção dos formulários de formatos desejados, sempre se perdem alguns milímetros de aparas ou "refilos". Os gráficos estimam que, entre as várias operações de corte e acabamento necessárias para a fabricação dos formulários, deve-se contar com a perda de $5 \mathrm{~mm}$ em cada extremidade do impresso. Assim, para calcular quantos formatos podemos obter de uma resma, acrescentamos $10 \mathrm{~mm}$ a cada dimensão do formato, obtendo-se, por exemplo, para o formato "A-4" as dimensões brutas: $220 \times 307 \mathrm{~mm}$. Obteremos, pois, nove formatos "A-4" da resma "BB" (com a sobra de $40 \mathrm{~mm}$ ).

Certa emprêsa resolveu mandar imprimir suas notas fiscais no formato arbitrário $230 \times 325 \mathrm{~mm}$. O leitor poderá verificar que não se tiram oito fôlhas nessas dimensões de uma fôlha de resma "BB", desde que se levam em conta os $10 \mathrm{~mm}$ de "refilo" para cada formato. Adotando-se outro formato ( $230 \times 315 \mathrm{~mm}$ ), obtêm-se oito impressos em cada fôlha. Porém, com o formato-padrão, $220 \mathrm{x}$ $307 \mathrm{~mm}$, obtêm-se, como vimos, nove impressos, o que constitui apreciável ganho em relação aos formatos arbitrários. Caso curioso é o de uma editôra cujo material redacional é totalmente escrito em laudas de $250 \times 297 \mathrm{~mm}$, de comprimento normalizado, mas de largura $40 \mathrm{~mm}$ maior que o padrão. Essas laudas não cabem em pastas suspensas, o que torna difícil seu arquivamento, além de constituir injustificável dispêndio de papel.

Os formatos padronizados são econômicos. Sua entrega pelas gráficas é mais rápida do que a dos formatos excecionais. Entretanto, apesar das vantagens que proporcionam, poucas são as emprêsas nacionais que adotam formatos padronizados em seus impressos. É certo, porém, que em futuro próximo a padronização dos papéis ganhará terreno, pois além de outras circunstâncias que tendem a apressá-la, o Govêrno Federal, através do Decreto n. ${ }^{\circ}$ 
4150 , de 21 de novembro de 1962, instituiu o regime obrigatório da adoção de normas técnicas nos contratos de obras e nos contratos de compras firmados por e com órgãos públicos.

O administrador deverá evitar formulários excessivamente grandes ou pequenos; ambos são difíceis de manusear e arquivar. Aquêles devem ser dobrados para manuseio e arquivamento, o que é incômodo; e êstes perdem-se fàcilmente, porque tendem a cair das pastas ou se extraviam sôbre as mesas e por dentro das gavetas.

GRAMATURA DO PAPEL

A espessura do papel é expressa em gramas por metro quadrado. E a gramatura. As gramaturas mais comuns de papel são $30,45,62,72$ e 150 . A partir da gramatura 180 entramos no domínio da cartolina ou cartão, cujas gramaturas principais são $180,240,300,350$ e 500 . Os comerciantes usam, também, para exprimir a espessura, o pêso, em quilos, da resma de $\mathbf{5 0 0}$ fôlhas.

O papel é comprado por quilo, de modo que uma fôlha de gramatura 45 custa $50 \%$ mais do que uma fôlha de gramatura 30 de um papel de tipo e qualidade idênticos. Substanciais economias podem ser realizadas quando se atenta para a gramatura do papel utilizado. Por exem plo, certa repartição imprimia apostilas em papel de gramatura 45 , translúcido, que, para que se obtenha impres são nítida, só pode ser impresso de um lado. O papel de gramatura 72 pode ser usado de ambos os lados. Ao adotar, pois, a gramatura 72 , a repartição realizou ume economia de $20 \%$ no papel.

A resistência física que o documento deve ter determin a gramatura. Ordens de produção, que circularão por mui tas mãos, ou fichas de inventário perpétuo, manuseada repetidas vêzes, serão confeccionadas em cartolina. Já uma autorização de saída de empregados ou de veículos de vida efêmera, será feita em papel leve. 
O papel de gramatura baixa possui outras vantagens: permite a datilografia de oito a dez cópias legiveis; a franquia. postal é menor; ocupa menos espaço nos arquivos .

TIPO DO PAPEL

O tipo de papel a ser usado para a confecção dos formulários depende dos seguintes fatôres:

A) Modalidade de preenchimento - Se fôr preenchido a tinta, dever-se-á usar papel não-absorvente; se fôr datilografado, um papel absorvente será satisfatório; a maioria dos formulários cai na primeira categoria.

B) Destino do documento - As vias principais, destinadas a um fornecedor, a um cliente ou a um diretor serão. impressas em papel de qualidade melhor que a do papel usado nas vias fixas do talão, que permanecem em mãos do remetente.

C) Duração do arquivamento - Os documentos que requerem longa conservação são manufaturados em papéis de melhor qualidade que a dos logo descartados; os papéis: à base de trapos e linho conservam-se melhor do que os fabricados com celulose.

Sob o aspecto de confecção de formulários, os papéis classificam-se em quatro categorias:

- Papéis para impressão. Exemplos: bouffant, acetinado, jornal, couché.

- Papéis para escrever. Exemplos: apergaminhado, sulfite, flor-post, superbond .

- Papéis para embalagem. Exemplos: manilha, kraft.

- Papéis especiais. Exemplos: eletróide.

Dos papéis para impressão o tipo bouffant é muito usado na impressão com máquinas de escritório, como o mimeógrafo e o Multilith. O tipo "acetinado", característico das revistas, e o tipo "jornal" ou "áspero" são também usados para certos formulários. Absorvem a tinta e borram, não. servindo em geral para escrever. 
Os papéis para escrever constituem a base da maioria dos formulários. Não devem borrar. O tipo "apergaminhado" utiliza-se para documentos de grande responsabilidade, como diplomas, que devem conservar-se por mais de 25 anos. O tipo denominado comercialmente "sulfite" é usado para correspondência e para os formulários comuns, cujo prazo de conservação esteja entre 5 e 10 anos. As vias de cópia e correspondência aérea são manufaturadas nos papéis "flor-post" e "superbond". As melhores qualidades dêsses últimos tipos servem para documentos contábeis e livros fiscais. O papel para embalagem tipo "manilha" é usado para fazer etiquêtas . Dentre os papéis especiais destaca-se o "eletróide", com o qual são feitos os cartões para máquinas de processamento de dados.

CÔR DO PAPEL

Como o papel de côr é, em geral, 10 a $15 \%$ mais caro do que o papel branco, convém restringir o seu uso aos seguintes casos:

- Quando se quer chamar a atenção sôbre certos formulários ou instruções, pelo seu caráter de urgência ou de importância; cartas que reclamam ação imediata, por exemplo.

- Quando se quer distinguir, umas das outras, as diversas vias de um formulário; os remetentes e destinatários identificam mais fàcilmente as vias de côres diferentes.

TEXTO

Ao confeccionar o formulário, deve-se ter em mente dez regras relativas ao texto:

1. $\left.{ }^{a}\right)$ Inclusão de todos os tópicos necessários - Todos os tópicos necessários ao registro e à transmisão da informação desejada serão incluídos no texto. Vê-se, por exemplo, que a lista de materiais para montagem de rádio reproduzida na Figura 8 deixou de incluir colunas adequadas para a anotação de informações importantes: número 
de peças por rádio; matéria-prima da qual a peça é feita (plástico, aço, cobre etc); pêso; origem da peça (fabricada em casa, importada, comprada na praça etc.); outros modelos nos quais o componente é usado. Devem, também, ser incluídos tópicos que tornem mais rápido o preenchimento do formulário. Assim, por exemplo, fichas de tomadas de pedidos, sob forma de listas nas quais estão impressos os nomes de todos os produtos da emprêsa, facilitarão o preenchimento rápido e legível do pedido por parte dos vendedores, que sòmente terão que marcar as quantidades encomendadas pelo cliente.

2. a) Exclusão de todos os tópicos desnecessários - Os tópicos desnecessários serão excluídos do formulário a fim de que não se perca tempo com o seu preenchimento e leitura. Informações supérfluas, indiscretas ou embaraçosas são, muitas vêzes, pedidas nos formulários de solicitação de emprêgo, nos quais o candidato deve mencionar, por exemplo, os nomes de seus avós, o número e a profissão dos irmãos, seus defeitos físicos e as causas pelas quais saiu dos empregos anteriores.

3. a) Definição inequívoca dos têrmos usados - Os têrmos usados em formulários não podem permitir interpretações equivocas. Assim, por exemplo, no formulário da Figura 9, que representa uma ficha de inspeção de peças por amostragem estatística dupla, o item "Nome" deveria ter sido intitulado "Artigo"; o item "Código" deveria ser "Código da peça"; o item "Data" deve ser entendido como "Data da inspeção"; finalmente, o tópico "Quantidade" poderia ser melhor explicitado como "Número de peças recebidas".

Em geral, nos formulários deve-se tentar definir com precisão certas palavras, notadamente:

- Data - A "data" numa ordem de fabricação pode ser qualquer das seguintes: data da emissão do pedido que irá gerar essa ordem de fabricação; data da recepção do pedido pelo departamento de planejamento da produção; data da emissão da ordem de fabricação pelo planejamento; data prevista para o início da fabricação; data prevista 
para o término da fabricação; data prevista para a entrega ao cliente.

- Número - O "número", se não fôr explicitado, poderá ser interpretado como quantidade, número de série ou indicação de tamanhos .

FIGURA 8: Lista de Material

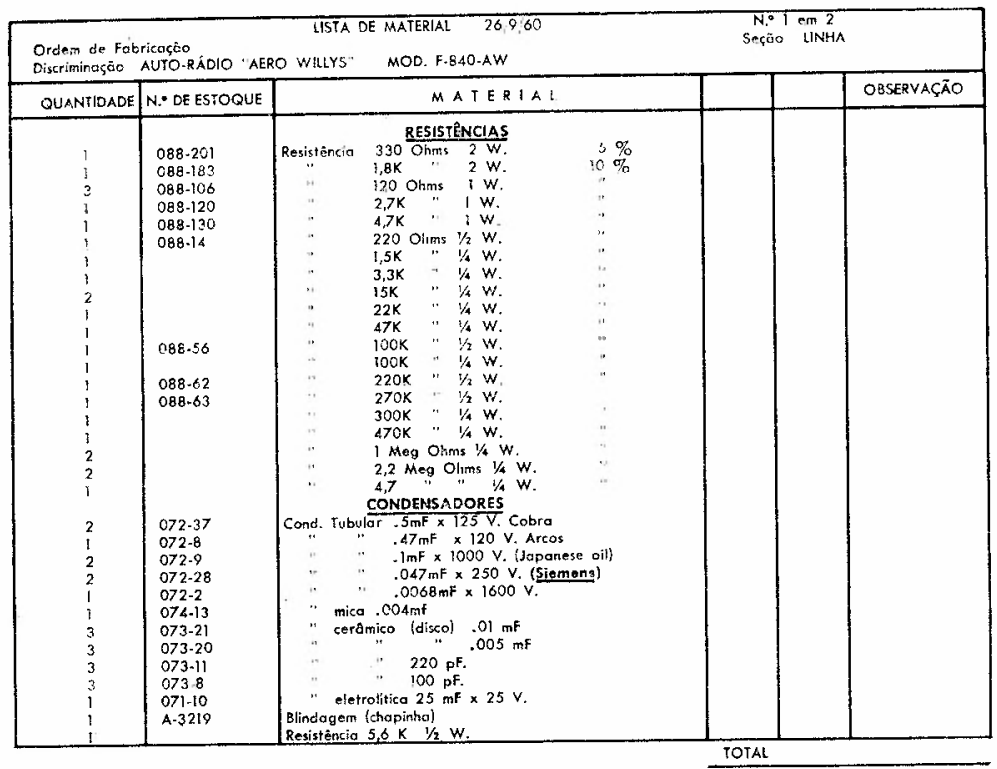

- Custo - Deve-se explicar se o "custo" é unitário ou total, de fabricação ou geral; médio ou da última compra; com inclusão ou não do impôsto de consumo e do frete, etc..

- Quantidade - Convém deixar claro se as unidades são quilos, litros, dúzias ou grosas .

Nos formulários preenchidos por pessoas estranhas à organização é necessário esclarecer se o "enderêço" é o da residência ou o da entrega de correspondência, se o "preencher" é com letra maiúscula ou minúscula, com tinta ou a lápis, se o "título" é o grau colado em universidade ou o cargo ocupado no último emprêgo. 


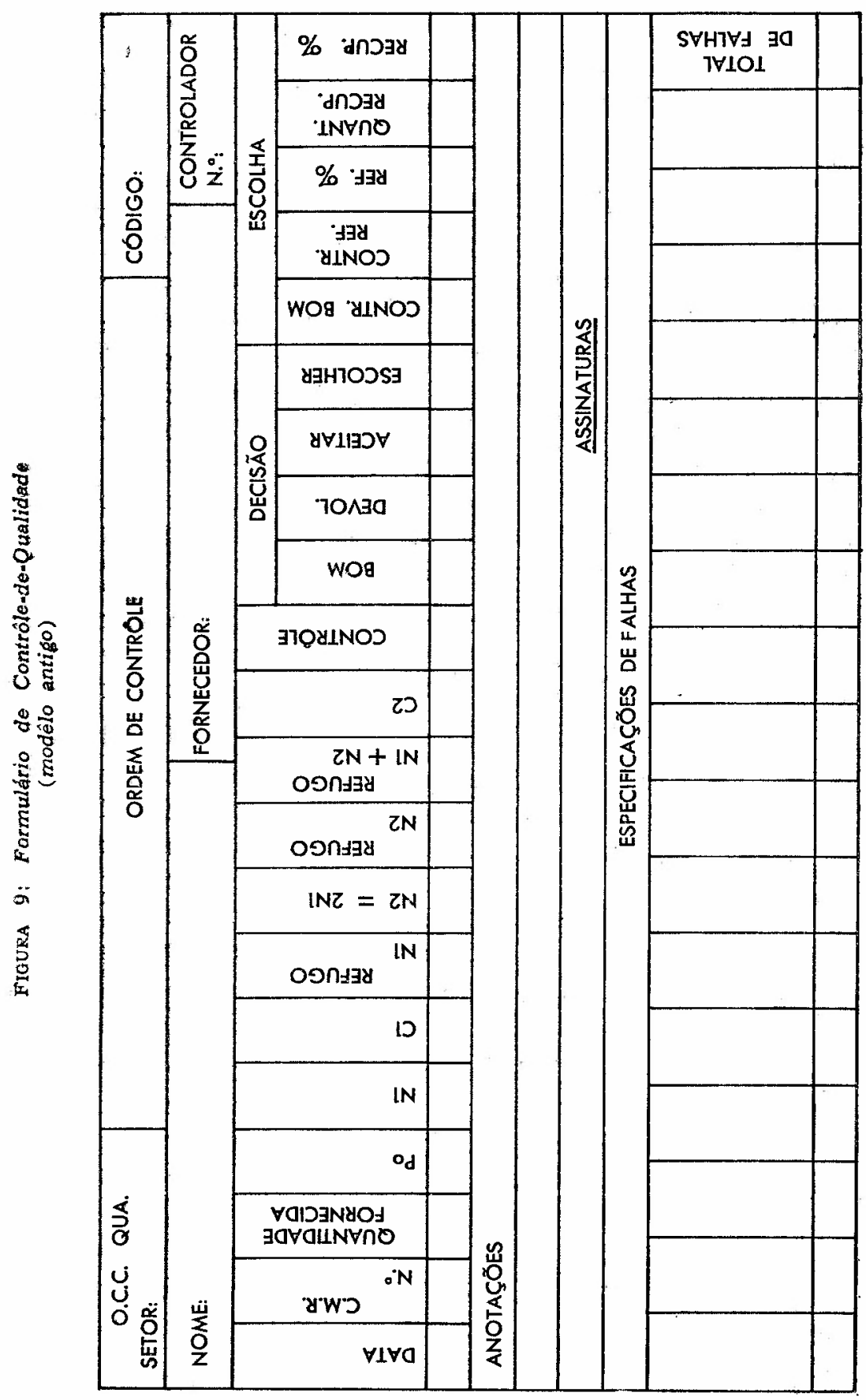




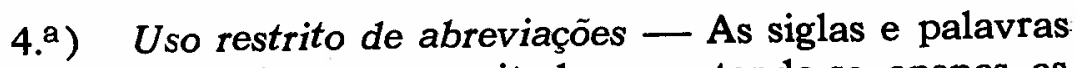
incompletas devem ser evitadas, mantendo-se apenas as que se fizerem de todo necessárias para uso racional do espaço. Por exemplo, "DEP. PROD." pode significar departamento de produção ou depósito de produtos; "N. " $^{\circ}$ o número de código da peça fabricada, o número de peças fabricadas ou o número de fabricação do lote; "Ass." é assinatura ou assistente? Abreviações de têrmos estrangeiros devem ser abolidas de formulários nacionais. Por exemplo, "J . T." (job ticket); "P.O." (production order). Na Figura 9 o item "C.C. Qua." significa Contrôle Central de Qualidade; “C.M.R." é o número de contrôle do material recebido; em lugar de "DEVOL." deveria estar escrito DEVOLVER; "REF!" é refugo; em lugar de "ESCOLHER" deveria estar escrito "escolher $100 \%$ ", etc. .

É raro que o formulário seja acompanhado de instruções para o seu preenchimento; convém que contenha sòmente têrmos claros e palavras que sejam um guia e não um estôrvo para o fácil preenchimento.

5. Escolha de um título - Todo o formulário deve ter um título que permita sua identificação imediata. O título será o mais descritivo possível, a fim de definir com precisão a função exata do formulário e impedir que seja confundido tom outro. O título "ordem de contrôle" não é feliz (Figura 9); melhor seria "boletim de inspeção de recebimento".

6. a) Numeração genérica - Cada formulário possuirá um número genérico de identificação, que será impresso nêle, em geral no canto esquerdo inferior, em algarismos pequenos. O número facilitará a identificação do formulário. É preferível adotar uma única seqüência numérica para todos os formulários da emprêsa a codificá-los por departamentos de origem.

$7_{1}^{\text {a }) ~ N u m e r a c ̧ a ̃ o ~ i n d i v i d u a l ~-~ C a d a ~ f o r m u l a ́ r i o ~ p o s s u i r e ́ ~}$ um número de identificação individual, impresso em alga rismos grandes no seu canto superior direito (Figura 10) A seqüuência numérica tem por finalidades, através do con trôle de sua continuidade, verificar se nenhum funcionáric 
Figura 10: Fornulário de Contrôle-de-Qualidade

Ficha de Inspeção de Recebimento (modêlo nôvo)

\begin{tabular}{|c|c|c|c|c|}
\hline CIA. BRASIL & RA DE & E TELEVISÕES & & N. 22401 \\
\hline $\begin{array}{l}\text { Contrôle } \\
\text { Central de } \\
\text { Qualidade }\end{array}$ & Setor: & $\begin{array}{l}\text { Ficha de Inspeção } \\
\text { Data do recebimento: }\end{array}$ & $N .^{\circ}$ de & recebimento \\
\hline
\end{tabular}

Artigo:

Código:

Fornecedor:

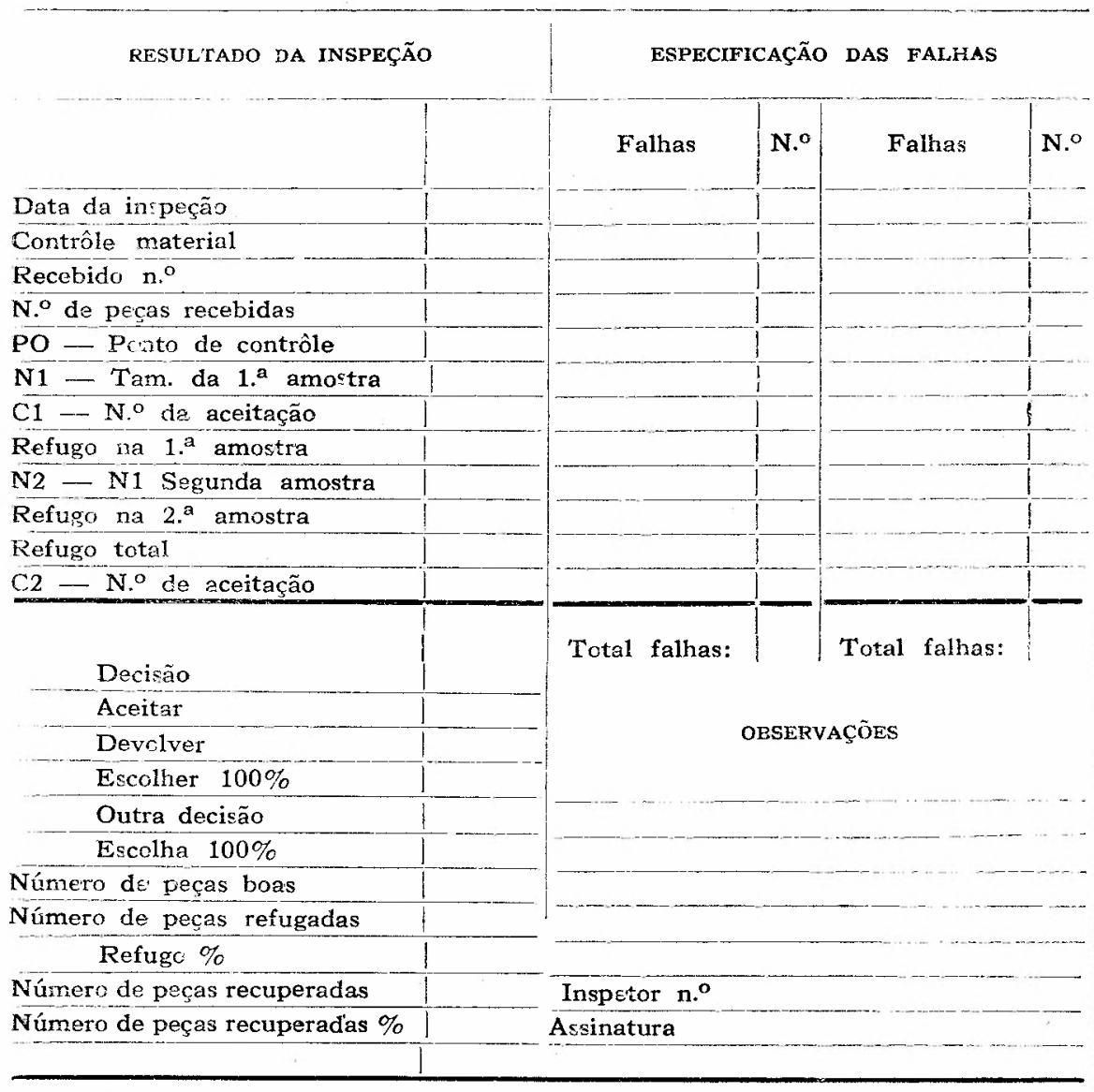

Mod. 524. 20.000 a $23.000 \times 6-2 / 63$ 
teria feito uso indevido do formulário, o que é particularmente importante para pedidos de compra, e se nenhum formulário teria sido extraviado ou se seu trâmite não estaria atrasado, contrôle êsse essencial para o processamento regular de pedidos de venda e de ordens de fabricação. Ademais, a numeração, em seqüuência, de certos documentos (notas fiscais, por exemplo) é determinação legal.

8. a) Registro da data e da série de impressão - É vantajoso colocar a data de impressão do formulário no canto esquerdo inferior e pôr no mesmo local o número da série de impressão.

Assim, por exemplo, a marcação 20000 a $23000 \times 6-$ $-2 / 63$ (Figura 10) indica que em fevereiro de 1963 foram impressos 3000 formulários, e que os números individuais dos formulários dêsse lote vão de 20000 a 23000 . O símbolo " $x$ 6" significa que se trata de talão com seis vias. Essas indicações objetivam permitir, pelo confronto com o número individual do formulário, a estimativa rápida do estoque existente, bem como do seu ritmo de consumo, o que é essencial para a encomenda do formulário no devido tempo ou para a sua atualização.

9. a) Colocação de nome e enderêço da emprêsa - Todos os formulários, internos e externos, devem trazer impressos no cabeçalho a firma, o nome e/ou o emblema do estabelecimento. Essa providência não faz perder muito espaço e assegura isenção do impôsto de consumo sempre que os formulários sejam adquiridos de uma tipografia, pois a lei presume que não serão revendidos, mas, sim, destinados a uso próprio. E mais difícil que pessoas pouco escrupulosas se apoderem de papel de correspondência timbrado ou de documentos marcados com a razão social da companhia. Os formulários externos devem ter, impressos, o enderêço da emprêsa e outras indicações legais, tais como o seu número de inscrição na Junta Comercial e como contribuinte do impôsto de vendas e consignações.

10. a) Indicação do remetente e do destinatário - No formulário será deixado espaço para a indicação do nome 
da pessoa ou seção remetente, bem como para sua assinatura ou carimbo. Cada via será marcada claramente com o nome, símbolo ou côr da seção a que se destina.

\section{DISPOSIÇÃO GRAFICA}

Três considerações são importantes para obter boa disposição gráfica no formulário.

1. $\left.{ }^{a}\right)$ Seqüência lógica no arranjo dos têrmos - Para facilitar o preenchimento e a leitura convém que os itens sejam dispostos e agrupados em seqüência lógica. Assim, por exemplo, a assinatura deve constar da última linha; as indicações devem seguir-se no sentido natural de leitura, da esquerda para a direita e de cima para baixo, especialmente quando o formulário fôr preenchido a máquina. Quando fôr necessário preencher o formulário a máquina, os tópicos devem ser impressos acima ou à esquerda, e não abaixo das linhas, a fim de o rôlo não dificultar a visão do datilógrafo. Quando fôr necessário fazer adições convirá colocar os dados a serem adicionados em colunas e não em linhas. Nos formulários que serão preenchidos por datilografia convém ainda dispor os dizeres em linhas horizontais contínuas, de maneira que não haja necessidade de muitos ajustes no alinhamento, e fazer coincidir a distância vertical entre as linhas com os espaçamentos padronizados das máquinas de escrever. Quando o formulário deve ser preenchido por diversas pessoas convém indicar claramente as separações por meio de linhas grossas ou de setas.

Evite-se ter de virar o formulário para preenchimento ou leitura. Não usar cabeçalhos verticais ou inclinados. Não usar o reverso do papel, exceto para colocar anotações impressas, como se faz nos reversos das ordens de compra, notas fiscais e apólices de seguro. E incômodo ter de virar a fôlha para a leitura das informações e, ademais, o reverso da fôlha, muitas vêzes, suja-se por contato com as mesas. 
Gráficos, histogramas, polígonos de séries temporais serão sempre preferiveis a enumerações de algarismos, pela rapidez de preenchimento e de visão que proporcionam.

2. $\left.{ }^{a}\right)$ Reserva de espaço para as margens - Deve-se reservar $3 \mathrm{~cm}$ à esquerda da página para ser possível arquivar o formulário em pastas grampeadas, e $1,5 \mathrm{~cm}$ para arquivamento em classificadores.

3. a) Reserva de espaço para observações - É sempre conveniente deixar espaço correspondente a algumas linhas ou colunas, para colocação de notas e observações eventuais.

Seguindo êsses lembretes, o administrador obterá um formulário prático, de preenchimento e leitura agradáveis. A Figura 10 mostra o formulário da Figura 9, resstudado para satisfazer tôdas as regras indicadas.

\section{CONCLUSÃO}

Pelo fato de ter sido em geral negligenciado, o estudo dos formulários constitui área onde a racionalização permite realizar consideráveis economias. Os administradores não dedicam muito tempo à racionalização dos formulários, talvez por causa do preconceito de que cuidar da "papelada" é próprio de um "burocrata" e, portanto, corstitui atividade desprezível. Na medida, porém, em que o administrador crie formulários úteis, elimine os supérfluos e melhore os existentes, êle não é um "burocrata", mas um produtor. Uma hora dedicada à melhoria dos formulários, conforme as regras mencionadas, reverterá em centenas de horas poupadas no seu preenchimento, leitura e arquivamento. E assim que o estudo pormenorizado das operações burocráticas permite eliminar muita "burocracia". 